\title{
Isolation Of Salmonella Gallinarum From Poultry Droppings In Jos Metropolis, Plateau State, Nigeria
}

\author{
* ${ }^{1}$ Okwori A.E.J., ${ }^{2}$ Ogbe R.J., ${ }^{3}$ Chollom S. C., ${ }^{4}$ Agada G. O. A., \\ ${ }^{1}$ Ujah A., ${ }^{5}$ Okwori, E., ${ }^{1}$ Adeyanju O.N., ${ }^{1}$ Echeonwu G.O.N.
}

${ }^{1}$ Department of Medical Microbiology, Federal College of Veterinary and Medical Laboratory Technology, Vom - Jos, Nigeria. ${ }^{2}$ Department of Veterinary Physiology, Pharmacology and Biochemistry, University of Agriculture, Makurdi, Nigeria. ${ }^{3}$ Viral Research Department, National Veterinary Research Institute, Vom,

Nigeria. ${ }^{4}$ Central Diagnostics Laboratory, National Veterinary Research Institute, Vom, Nigeria.

${ }^{5}$ Microbiology Department, Federal Medical Centre Keffi.

\begin{abstract}
Fowl tyhoid is host adapted to avian species and is considered to pose a minimal zoonotic risk throughout the world. This work is aimed at isolating Salmonella gallinarum from poultry droppings used for manure in Jos metropolis. One hundred and fifty samples of poultry droppings from fifty poultry houses in Vom, Kuru, Bukuru and Jos towns of Plateau State were sampled for the presence of Salmonella gallinarum using cultural, biochemical and biological properties to identify the isolates. Two isolates (1.3\%) from two poultry farms were positive for Salmonella gallinarum. Other bacteria concurrently isolated included: Proteus species, Escherichia coli, Staphylococcus species, Klebsiella species, Pseudomonas species and lactobacilli. The presence of Salmonella gallinarum calls for improved poultry farm hygiene and the use of effective broad spectrum antibiotics. Detection of Salmonella gallinarum in poultry droppings in this study poses health hazards to other uninfected birds especially those at free range.
\end{abstract}

Key words: Poultry droppings, Salmonella gallinarum, Jos, Nigeria

\section{Introduction}

Fowl typhoid caused by Salmonella gallinarum is recognized worldwide as a disease of social and economic significance (Shivaprasad, 1997). In Africa it has been reported in many countries including Tanzania, Uganda (Okoj, 1993), Senegal (Arbelot et al., 1997), Nigeria (Sa'idu et al., 1994) and Morocco (Bouzoubaa et al., 1987).

It is a septicaemic disease that affects primarily chicken and turkey, although natural infections in many other avian species have been reported (Shivaprasad, 1997., Wray et al.,1996). Although Salmonella gallinarum infection is frequently considered as a problem of adult and grower chicken, chicks are often affected. Efforts at controlling fowl typhoid through the application of a co-ordinated policy of hygienic measures, together with serological testing and slaughter of positive reactors, have led to the seemingly eradication of Salmonella gallinarum in many developing countries (Barrow, 1999), however, fowl typhoid which is caused by this pathogen remains a leading disease of the poultry industry in many areas of the world.

Acute disease conditions of Salmonella gallinarum infection in chickens include respiratory distress and depression with a characteristic clinical sign of mucoid yellow diarrhea. In sub-acute outbreaks, sporadic mortality over a long period is experienced while in chronic disease condition, loss of appetite and severe anaemia is observed. The transmission of Salmonella gallinarum can be through bird droppings of infected birds, bird carcasses and laid eggs. It could be introduced by importation of live infected chicken and hatched eggs. Mechanical spread may be by humans, wild birds, mammals, flies, ticks, feedsacks, etc (Steigh and Duguid, 1989).

For the past few decades, poultry production has become increasingly organized, specialized and integrated into an industry of major national and international importance (Mai et al., 2004; Khan et al., 2007). As a result, poultry diseases are every poultry farmer's nightmare. The economic losses attributed to this infection are enormous and in most cases unquantifiable. Early detection of the disease in any locality can help reduce/eliminate the losses that may occur in the event of the disease outbreak. These prompted the current research which was targeted at the sampling of poultry droppings from farms in the study area for the presence of Salmonella gallinarum.

Salmonella gallinarum biovars Pullorum and Gallinarum have been eradicated in commercial poultry productions in the developed world, but are still important in backyard flocks as well as the developing world (Woodward et al., 1997). This study is aimed at isolating Salmonella gallinarum from poultry droppings used for manure. This is intended to help elucidate some of the environmental sources of Salmonella infections in Jos metropolis, Nigeria. 


\section{Materials And Methods}

All the samples were collected within the Jos Metropolis, the capital of Plateau State in Nigeria. Poultry droppings were collected from poultry farms once every week for six months. Sterile spatulas were used to collect samples of freshly passed poultry droppings in sterile universal sampling bottles. The droppings were collected from litter at random points and transported to the laboratory where they were analysed within one hour from the time of collection as adopted by Orji et al., 2005.

\section{Study Area and Sampling}

150 samples of poultry droppings were collected from farms within Vom, Kuru, Bukuru and Jos areas. Samples were collected at 3 points in each poultry farm once in a week. This was done to have a good representation and distribution of the organisms in question.

\section{Sample Processing}

The isolation of Salmonella from poultry droppings was carried out according to the method described by Barrell, 1980 and Orji et al., 2005.

\section{IDENTIFICATION OF ISOLATES}

Salmonella-typical colonies on the plates (pale or colorless with or without black centers on deoxycholate citrate agar (DCA) and a bright red color on propylene glycol deoxycholate agar (PGDA) were cultured onto triple sugar iron agar (TSIA) slants, urea agar lysine broth and incubated at $37^{\circ} \mathrm{C}$ for $24 \mathrm{hrs}$. Suspected Salmonella colonies were further subjected to phenotypic test using API 20E strips (Sharma et al., 1990 ).

\section{SEROLOGICAL TEST}

Serological typing was carried out by rapid plate agglutination test as described by O.I.E.(1996). The antigen used for both methods was locally produced as described by O.I.E. (1996) using a local Salmonella gallinarum strain (Mdegela et al., 2000).

\section{STATISTICAL ANALYSIS}

Statistical analysis was precluded due to inadequate data settings.

\section{Results}

The distribution of samples from different sources and the different isolates are shown in Table 1. Salmonella gallinarum was isolated from two farms. These farms are located in Vom and Bukuru. Other organisms consistently isolated included; Escherichia coli, Klebsiella species, Proteus species, Pseudomonas species, Streptococcus species, Staphylococcus species and Lactobacillus species.

Table 1: Distribution of samples and isolates from different locations

\begin{tabular}{lllllll}
\hline Sources & Vom & Kuru & Bukuru & Jos town & Total & Percentage \\
\hline No of Poultry & 20 & 15 & 13 & 2 & 50 & \\
Nos of samples & 60 & 45 & 39 & 6 & 150 & \\
Isolates & & & & & & \\
Salmonella gallinarum & 1 & 0 & 1 & 0 & 2 & 1.3 \\
Escherichia coli & 18 & 11 & 12 & 2 & 43 & 28.6 \\
Klebsiella species & 15 & 13 & 9 & 1 & 38 & 25.3 \\
Pseudomonas species & 13 & 9 & 6 & 1 & 29 & 19.3 \\
Proteus species & 14 & 8 & 7 & 0 & 29 & 19.3 \\
Staphylococcus species & 4 & 2 & 5 & 0 & 11 & 7.3 \\
Lactobacilli species & 9 & 4 & 2 & 0 & 15 & 10 \\
\hline
\end{tabular}

\section{Discussion}

Fowl typhoid is a poultry disease that has decreased in incidence over the years by application of basic management procedures (Saif et al., 2003).

In Nigeria, especially in many parts of Plateau state, poultry droppings serves as a good source of manure for the cultivation of crops and vegetables and are sold to farmers at the rate of about N150 (1\$) per bag of 10-15 kg (Orji et al., 2005). The farmers use poultry droppings for the dual purposes of enriching the soil for 
improved crop yields and economically disposing of the droppings. However, the addition of the poultry droppings directly into soils without any form of treatment poses some public health problems since they contain pathogenic microorganisms. Poor sanitary habits have been reported to be contributing to the persistence of the disease (Jordan and Pattison, 1999) and have led to enteric disease endemicity. Sanitary awareness has been found below average from our findings while interacting with the farmers in the study area. This is similar to the findings of Orji et al., 2005 in Awka, Anambra state, Nigeria. The pathogenic microorganisms can contaminate the surrounding crops and vegetables and become a source of infection, especially when such crops or vegetables are eaten raw or brought home where they can contaminate other materials.

Our findings showed the presence of Salmonella gallinarum in some poultry droppings in the study area. This is similar to the serological prevalence of Salmonella gallinarum infection in scavenging local chickens reported from Mauritania (Bell et al., 1990), Morocco (Bouzoubaa et al., 1992), Benin (Chrysostome et al., 1995) and Senegal (Arbelot et al., 1997). It is evident that the infection rate in scavenging local chickens is normally low. Irrespective of the low prevalence, it should be regarded as significant owing to its devastating effect on infected birds and the poultry industry at large. Fowl typhoid is transmitted both vertically and horizontally (Wray et al., 1996). In cases where the disease is transmitted horizontally, contaminated feed and drinking water are the main sources of infection and, under extensive systems of management, as in village poultry production, the chances of chickens eating and drinking contaminated materials are minimal. Much higher prevalence rates of $33.8 \%$ in individual birds and $71.2 \%$ on a flock level have previously been reported in Tanzanian scavenging local chickens (Minga et al., 1987) using the same methods. Apparently, the infection rate can vary considerably with time, but the reason for this remains unknown (Mdegela et al., 2000). The possibility that the serological positivity was due to infection with other Group D Salmonella, such as Salmonella enteritidis or Salmonella pullorum cannot be excluded.

It is possible that, under poor biosecurity systems, commercial chickens may act as one of the sources of Salmonella gallinarum for scavenging local chickens.

Poultry droppings have been known to be constant sources of circulating poultry diseases,

previous studies performed in Tanzania and Senegal have reported higher serological prevalences in commercial layers than those observed here in Nigeria (Orji et al., 2005). Generally, Salmonella gallinarum - infected chickens are not efficient excretors, unlike birds infected with motile Salmonella, that cause enteric rather than systemic infections (Smith and Tucker, 1980).

Owing to the indiscriminate use of antibiotics, many pathogens have developed resistance to antibiotics. The continued use of these pathogen resistant drugs could lead to development of highly resistant strains of the pathogen which can spread in the environment causing major disease outbreaks of an enormous magnitude in future.

\section{Conclusion}

Having identified the presence of Salmonella gallinarum in poultry droppings in the study area, these poultry wastes could pose a health hazards to other uninfected birds especially free range. In commercial chickens, regulations have to be enforced to ensure that there is an effective flock monitoring system at all levels of production, aimed at detecting Salmonella gallinarum infection and instituting appropriate control measures, as recommended by Shivaprasad (1997).

Further studies on the antibiotic susceptibility testing of bacterial pathogens of poultry origin is highly recommended.

\section{Acknowledgements}

The authors thank the Management and the Provost, Federal College of Veterinary and Medical Laboratory Technology, Vom, Nigeria for permission to publish this paper.

\section{References}

[1] Shivaprasad, H.L. (1997). Pullorum disease and fowl typhoid. In B.W. Calnek., H.J. Barnes., C.W. Beard., L.R. McDougald \& Y.M. Saif (Eds.), Disease of Poultry 10th edition (pp. 82- 96). Ames, IA: Iowa State University Press.

[2] Okoj, L. (1993). Diseases as important factors affecting increased poultry production in Uganda. Der Tropenlandwin, Zeitschrift in dentropen and Subtropen Jahrgag, 94, S37-S44.

[3] Arbelot, B., Dayon, J.F. Mamis D. Gneye J.C. Tall, F and Samb H. (1997). Sero-survey of Dominant avian disease in Senagal; Mycoplasmosis, Fowl Typhoid and Pullorum disease, Newcastle, infectious bursal and infections bronchitis disease. Revue d' Elevage et de Medicine veterinarier des Pays tropicaus, 50, 197-203.

[4] Saidu, L., Abdu., P.A. Umoh, J.U and Abdulahi, U.S (1994). Disease of Nigerian indigenous chickens. Bulletin of Animals Health Production in Africa, 42, 19-23.

[5] Bouzoubaa K.,K.V. Nagarya, J. A. Newman, and B.S. pomeraj (1987). Use of membrane proteins from Salmonella gallinarum for prevention of fowl typhoid infection in chickens. Avian Dis. 31: 699-704 Cheesbrough, M.(2000). District Laboratory practice in Tropical Countries part 2 (pp. $132-142$ )

[6] Wray, C., Davies, R.H and Corkish, J.D (1996). Enterobacteriaceae. In F.T.W. Jordan and M. Pattison (Eds). Poultry Diseases $4^{\text {th }}$ edition (pp 9-43) London; Saunders company Ltd. 
[7] Barrow, P.A. M. A. Lowell. C.K. Murphy, and K. Page (1999). Salmonella infection in a commercial line of ducks: Experimental studies in virulence, Intestinal colonization and immune protection. Epidermiol infect 123: $121-132$.

[8] Steigh JD, Duguid JP. (1989). Salmonella. In: 13th ed.. Collee JG, Duguid JP, Fraser AG, Marmion BP editor. Practical Medical Microbiology. Volume 2:New York: Churchill Livingstone p. 456-479

[9] Mai, H. M., Ogunshola, O.D. and Obasi, O L. (2004). Serological survey of te Newcastle disease and infectious bursal disease in local ducks and local guinea fowl in Jos, Plateau state, Nigeria. Revue Eleve Medical Veterinari pavstrop Tropica Pathologie Infectieuse Communication 57 (1-2): $41-44$

[10] Khan, M.A., Hussain, I., Siddique, M., Rahman, S.U. \& Arshad, M. (2007). Adaptation of a local wild Infectious bursal disease virus on chicken embryo fibroblast cell culture. International Journal of Agriculture and Biology, 9(6): 925-927.

[11] Woodward D.L., Khakhria R, Johnson W.M (1997). Human salmonellosis associated with exotic pets. J.Clinical Microbiol 35(11) 2786-2790

[12] Mike Uche Orji., Henry C. Onuigbo., Theodore I. Mbata (2005). Isolation of Salmonella from poultry droppings and other environmental sources in Awka. Nigeria International Journal of Infectious Diseases Volume 9, Issue 2, 86-89.

[13] Barrell RA. (1982). Isolations of Salmonellas from human, food and environmental sources in the Manchester area 1976-1980. J. Hyg (Lond).88:403-409

[14] Sharma, N. K., Doyle, P. W., Gerbasi, S. A. and Jessop, J. H. (1990). Identification of and related organisms. Journal of Clin. Microbiol. 21: 980-982.

[15] O.I.E. (1996). Fowl typhoid and Pullorum disease. In Manual of Standards for Diagnostic Tests and Vaccines (pp 532-538).

[16] Robinson H. Mdegela a b , Mmeta G.S. Yongolo a , Uswege M. Minga a \& John E. Olsen (2000). Molecular epidemiology of Salmonella gallinarum in chickens in Tanzania. Avian pathology 29:457-463

[17] Saif Y.M. barnes H.J., Glisson J.R., Fadly A.M. Mcdougald L.R., Swayne E.E. (2003). Diseases of Poultry; $11^{\text {th }}$ Edition. IOWA State Press. Ames IA, 567-582

[18] Jordan, FTW and Pattison, M (1999). Poultry diseases. (Fourth Edition) W.B. Sanders, Harcourt Brace and Coy Ltd. University press, Cambridge, U.K. Ltd.

[19] Bell, J.G., Kane, M. \& Lejan, C. (1990). An investigation of disease status of village poultry in Mauritania. Preventive Veterinary Medicine, 8, 291-294.

[20] Bouzoubaa, K., Lemainguer, K. \& Bell, J.G. (1992). Village chickens as a reservoir of Salmonella pullorum and Salmonella gallinarum in Morocco. Preventive Veterinary Medicine, 12, 95-100.

[21] Chrysostome, C.A.A.M., Bell, J.G., Demey, F. \& Verhulst, A. (1995). Seroprevalences to three diseases in village chickens in Benin. Preventive Veterinary Medicine, 22, 257-261.

[22] Minga, U.M., Kikopa, R., Minja, K.S.G.Z. \& Mwasha, J.D. (1987). The prevalence and improved serodiagnosis of fowl typhoid in Tanzania. Proceedings of the 5th Tanzania Veterinary Association Scientific Conference. (pp. 325-338). Morogoro: Tanzania Veterinary Association.

[23] Smith, H.W. \& Turcker, J.F. (1980). The virulence of Salmonella strains for chickens: their excretion by infected chickens. Journal of Hygiene, Cambridge, 84, 479-483. 